\title{
GOBIERNOS LOCALES Y EDUCACIÓN EN CHILE EN EL SIGLO XIX: UNA APROXIMACIÓN HISTÓRICA
}

\author{
Moyra Castro Paredes ${ }^{1}$ \\ Universidad de Talca - Chile \\ mocastro@utalca.cl
}

Recepción: 27/07/2010

Evaluación: 10/09/2010

Aceptación: 18/11/2010

Artículo de Reflexión

\section{RESUMEN}

La mayoría de los debates y análisis de la Municipalización Educativa en Chile se refieren a un fenómeno más bien contemporáneo. El artículo reconstruye desde los sucesos histórico-educativos el sistema escolar municipal, -de origen colonial- fundados en las obligaciones de los cabildos en la enseñanza de su territorio en los comienzos de la vida institucional del país. En razón de ello, se describen las expresiones educativas más relevantes de los pueblos originarios, las secuelas de la presencia hispana y el itinerario del siglo XIX, ligado a la organización del país y al desempeño de los gobiernos subnacionales. El texto finaliza con algunas reflexiones que contribuyen a la memoria educativa, no sólo para profundizar derroteros y eventuales restricciones, sino para aprovechar su trayectoria -educación y gobiernos locales- que otorga coherencia y significación a la cuestión educativa-local del presente.

Palabras clave: Política Educativa, Gobiernos Locales, Descentralización Educacional, Historia Política de la Educación.

\footnotetext{
1 Doctora en Educación, por la Universidad de Salamanca, Profesora e Investigadora Asistente. Instituto de Investigación y Desarrollo Educacional de la Universidad de Talca - Chile.
} 


\title{
LOCAL GOVERNMENTS AND EDUCATION IN CHILE INTHE NINETEENTH CENTURY: AHISTORICALAPPROACH
}

\author{
Moyra Castro Paredes ${ }^{1}$ \\ Universidad de Talca - Chile \\ mocastro@utalca.cl
}

\begin{abstract}
Most discussions and analysis of Educational Municipalization (small towns) in Chile refer to a phenomenon rather contemporary. The article reconstructs from historical and educational events the municipal school system, colonialhome-based on the tasks of the chapters in the teaching of their territory in the early institutional life of the country. Because of this, we describe the most important educational expressions of indigenous communities, the aftermath of the Hispanic presence and the itinerary of the nineteenth century, linked to the organization in the country and the performance of subnational governments. The text ends with some reflections that contribute to the memory of education, not only to deepen paths and any restrictions, but to make his career-education and local governments, which gives coherence and significance to the local educational question-present.
\end{abstract}

Key words: Education Policy, Education, Decentralization, Local Governments, Political History of Education. 


\section{INTRODUCCIÓN}

La política de descentralización educativa del siglo XIX es menos explícita en la historia oficial producto del modelo centralizado predominante. A saber, las prácticas desplegadas por el Estado-Nación, el dominio de minorías selectas, la burocracia administrativa, la concentración de los partidos políticos y las atribuciones del Poder Ejecutivo, aportaron precedentes cruciales en la subordinación de las comunidades locales. A pesar de la homogenización extendida por el Estado, la "identidad territorial siempre ha existido; no puede no existir." En educación, desde el nacimiento de la República la instrucción despertó gran interés por los nuevos gobernantes, situación que trascendió en lo político y técnico. En su inaugural intervención ordena el sistema presionando por las responsabilidades educativas de los Cabildos, como entidad pública y a los conventos como privados. Así se estructuraron estrategias para entregar, cuidar y mantener un sistema de enseñanza para niños jóvenes en cada jurisdicción. Posteriormente surgieron definiciones y prioridades que generaron debates y doctrinas, pero siempre enlazada a la historia educacional, la historia institucional y la de los pueblos que conformaron la nación.

El artículo forma parte de un proyecto de investigación ${ }^{3}$ y está dividido en cinco ciclos que señalan las expresiones históricas-educativas más relevantes de los pueblos originarios, la repercusión de la presencia hispana y el itinerario del siglo XIX, -organización del país y desempeño de los gobiernos localespasando por los primeros intentos de instrucción en la etapa independista y republicana, el papel de los cabildos en la concreción de un sistema de enseñanza, el desamparo de las atribuciones locales y la preeminencia del aparato estatal. Las referencias, condensadas pertinentemente y con fines dialécticos se analizan brevemente al interior de los avatares propios del país. De esta forma, los acontecimientos se relacionan con aspectos sociales, económicos, políticos e institucionales, de influencia directa e indirecta en las distintas etapas de la evolución educativa en Chile. Finaliza con algunas reflexiones en torno al imprescindible aporte de la memoria, no sólo para indagar los derroteros y las eventuales restricciones, sino para aprovechar la trayectoria de la educación y los gobiernos locales del siglo XIX, las dificultades implícitas, las iniciativas que se intentaron, las intenciones fracasadas, el peso socio-político y los avances en

2 VALENZUELA, Esteban. (1999): Alegato histórico regionalista. Santiago, Ediciones Sur, p. 13.

3 El artículo es parte del Proyecto PBCT - CONICYT PSD - 60 Fortalecimiento de la Investigación en Políticas Públicas en la Universidad de Talca. Línea de Investigación de Políticas Educativas de nivel Regional y Local. Instituto de Investigación y Desarrollo Educacional IIDE, Universidad de Talca.

Rev. hist. edu. latinoam. Vol. 15. Año 2010, pp. 93 - 124 
la escolarización. Puesto que toda memoria otorga coherencia y significación a la cuestión educativa-local del presente.

\section{La educación de nuestros primeros habitantes}

Desde hace miles de años, las tierras que hoy comprende Chile fueron habitadas por diversas agrupaciones humanas, "un territorio tan delimitado como el chileno -desierto, cordillera y mar- plantea la existencia de una organización social, o varias organizaciones, bien estructuradas," 4 como la relación y constitución de pueblos peculiares y diferenciados. Eran nómades, subsistían de la caza de animales y de su crianza, de la recolección de productos vegetales y dependiendo del lugar, de la pesca.

$\mathrm{Al}$ arribo de los españoles la población originaria ascendía aproximadamente a un millón de habitantes. La familia era extensa, compleja -centro de la organización social- y no jerarquizada. Los grupos reconocían un jefe como juez-consejero para regular conflictos y emprender acciones comunes, sin representar una organización social y política permanente. ${ }^{5}$ La existencia de enseñanza intencionada aparece en las crónicas de los primeros visitantes. En el interés de los padres en la fuerza y diligencia de sus hijos, sin enseñar a leer ni a escribir o un oficio ${ }^{6}$ y en la formación de shamanes con aprendices sometidos a disciplinas y exigencias mediatizadas por poderes sobrenaturales para alcanzar prestigio en su grupo. ${ }^{7}$ Por lo demás, para los araucanos, -uno de los pueblos nativos más difíciles de someter- la ejercitación física era vital.

La vida de la población durante la conquista española introdujo grandes mutaciones como su desplazamiento, trance íntimamente ligado a la instantánea disminución de sus tierras. ${ }^{8}$ Existían dos regiones diferenciadas. En el Norte y valle central la pacificación fue más expedita: sumisión del territorio, imposición de leyes y creencias, estratificación sociocultural como apropiación de terrenos y riquezas fueron previos a la formalización de las relaciones, y prosiguieron con fundación de ciudades, repartición de tierras y solares a los soldados en pago de sus servicios, incluidos sus propios habitantes. Allí se emplazaba la

\footnotetext{
4 BENGOA, José. (2000): Historia del pueblo mapuche. Siglo XIX y XX, pp. 11-71.

Santiago, LOM Ediciones, p. 22.

5 Ibídem, p. 31.

6 DE ROSALES, Diego. (1877): Historia General del Reyno de Chile, Flandes Indiano, Tomo I, Libro I, pp. 1-179. Valparaíso, Imprenta del Mercurio, p. 168.

7 LABARCA, Amanda. (1939): Historia de la enseñanza en Chile. Santiago, Editorial Universitaria. Publicaciones de la Universidad de Chile, p. 6.

8 SILVA, Fernando. (1962): Tierras y pueblos de indios en el Reino de Chile. Esquema histórico-jurídico, pp. 53-83. Santiago, Universidad Católica de Chile, p. 72.
} 
Real Audiencia y se producía la riqueza minera, agrícola y ganadera exportada al Virreinato. Y en el Sur, una sociedad más pobre y de sello guerrero configuraba la frontera de la guerra, más las autoridades políticas, militares y eclesiásticas. En estas circunstancias, los primeros defendían el territorio, frenaban potenciales invasiones y resistían amenazas de guerra.

Diversos historiadores coinciden que la ocupación y el control -los nuevos territorios para la historia occidental- de la Araucanía, debió enfrentar las escaladas libertarias, asaltos y rebeliones de los pueblos donde la guerra se convirtió en sobrevivencia. La resistencia se extendió casi tres siglos y es conocida como la Guerra de Arauco. En respuesta, se creó un ejército profesional permanente favoreciendo la presencia de oficiales entre las autoridades del Reyno de Chile. Desde ese momento, "los militares han sido un actor político relevante, y han ejercido una considerable influencia en la formación y desarrollo de su cultura política". ${ }^{9}$ A los efectos de la guerra prosiguió un intenso intercambio cultural y económico y masivos procesos de mestizaje. Al tenor de los hechos y para ir sosteniendo el modelo colonial, la administración asintió una negociación bilateral donde la corona reconocía la independencia de ciertos territorios respecto de la Capitanía General de Chile que, en la práctica no fue muy duradera.

Tales sucesos estuvieron ceñidos de enorme adversidad e incertidumbre. Más aún, su posición hegemónica, -considerando a los pueblos originarios como seres inferiores- admitía todo tipo de impunidad cuando la riqueza y el dominio estaban por delante. ${ }^{10}$ Por tanto, el interés del conquistador no se centró en una enseñanza sistemática sino en edificaciones de ciudades, explotaciones auríferas y siembras suburbanas para la subsistencia. Con todo, alzó una rápida formación a los lugareños, instruyendo en la fe y enseñando lectura por apremio de mano de obra para llevar a cabo dichos trabajos.

Los primeros esfuerzos educativos en el siglo XVI conllevan la petición de un maestro y la fundación de una escuela; ya que los hijos de familia española viajaban a Lima para estudiar. Tras la conquista arribaron los primeros sacerdotes que aportaron educación y evangelización en esta fase. Un siglo más tarde, las órdenes religiosas otorgaron las bases prácticas de la labor educativa en escuelas de primeras letras y en la formación de sacerdotes, cuya característica fue la

9 VERGARA, Jorge. (2001): El Estado y las organizaciones sociales en Chile. (Versión preliminar). Ponencia presentada en el Tercer Encuentro Latinoamericano ISTR-LAC, Buenos Aires, Argentina, p. 4.

${ }^{10}$ DONOSO, Andrés. (2008): Educación y nación. Al sur de la frontera. Santiago, Pehuén Editores, p.33. 
escasez alumnos y los privilegios sociales. La educación estaba condicionada por la sociedad que la transmitía, "permaneció esencialmente aristocrática, confinada a una clase selecta: los criollos, españoles y mestizos de clase alta." 11

El cabildo tiene su origen en la institucionalidad española. En su reconquista, la estructura peninsular contemplaba una división política y administrativa de territorios gobernada por un conde, representante del rey en cuestiones legales, económicas y militares y una asamblea formada por los hombres libres de la región. Durante la invasión árabe urgía instalarse en las zonas fronterizas a fin de defender los territorios conquistados y recuperar los ocupados. Para ello, la monarquía pactó con los pueblos el mando jurisdiccional, transfiriendo a la comunidad ventajas, privilegios, exenciones de tributos y fueros (concesiones de tierras, villas, iglesias, castillos) bajo el compromiso de fidelidad a la corona. A la anuencia de soberanía popular prosiguió una organización comarcal propia. "El Concejo ó Municipio medieval no fue sino la aplicación al territorio de la villa ó ciudad, segregada (...) del territorio señorial, de las instituciones judiciales y administrativas vigentes en estas circunscripciones de que antes había formado parte." 12

Desde fines del siglo XII hasta principios del XVII los ayuntamientos españoles se dotaron de autonomía y por ende, adquirieron numerosas funciones de bien público, usualmente adaptadas a costumbres y necesidades locales. En evolución equivalente a Europa "dejan bien pronto de surgir de la elección de los vecinos para transformarse en cuerpos que se renuevan por cooptación (es el caso de los cabildos más pobres) o por venta, a veces con garantía de transmisión hereditaria."13 Esto es, franquicias y atribuciones adquiridas, compras de derechos, incluso uso de violencia fueron comprimidas y alteradas por el abuso de ciertos grupos que perturbaron la gestión municipal. ${ }^{14}$ Todavía más, en el proceso político de lograr mayor control y menor disgregación, nombraron corregidores en cada gobierno local. Tales sucesos condujeron a la decadencia de la autonomía y a las secuelas de menoscabo en sus fueros y privilegios.

En Chile, la fundación de las ciudades trajo aparejada la apertura a la vida ciudadana ligada al Cabildo. Recién acontecida la conquista, la corona no pudo

\footnotetext{
${ }^{11}$ HARING, Clarence. (1972): El Imperio Hispánico en América (2 $2^{\mathrm{a}}$ ed.). Traducción de Horacio Pérez Silva, pp.164-240. Buenos Aires, Solar/Hachette, p.230.

12 DE HINOJOSA Y NAVEROS, Eduardo. (1903): Estudios sobre la Historia del Derecho Español. Madrid, Imprenta del Asilo de Huérfanos del Sagrado Corazón de Jesús, p. 17.

${ }^{13}$ HALPERIN, Tulio. (1972): Historia Contemporánea de América Latina (3a ed.). Madrid, Alianza Editorial S. A., p. 51.

${ }^{14}$ MOLINA, Miguel. (1996): El Municipio en América. Aproximación a su desarrollo histórico. Granada, Ediciones Adhara, S. L., p. 33.
} 
imponer su modelo altamente centralizado de administración imperial, y tanto en Chile como en América, autorizó el trasplante de la institución mediante leyes y documentos, con lo cual, durante un breve lapso, los conquistadores gozaron de autonomía gubernamental. ${ }^{15}$ La situación cambió con la restitución del centralismo, designando corregidores para evitar la pérdida de autoridad y limitar las iniciativas individuales. En otra perspectiva, las múltiples atribuciones del cabildo, casi sin límites precisos y alejados por un océano del poder, acrecentaron las expectativas y por consiguiente revivieron la institución, "(...) los legendarios aventureros que la realizaron, salidos, precisamente, de las aldeas de España -donde aún funcionaban los concejos abiertos- usaron las viejas costumbres municipales como medio poderoso de organización."16

En el transcurso del siglo XVII existían tres tipos de centros educativos: escuelas de primeras letras, escuelas de gramática y universidades pontificias. La enseñanza fue ampliándose hacia otros espacios de la sociedad y de "este interesante y secular proceso"17 nacieron las primeras escuelas públicas de los cabildos y en efecto, nuevas funciones municipales, aludiendo a la fiscalización de escuelas, maestros, disciplina y estudios. Sin embargo, "la situación de los cabildos no puede ser juzgada a la luz de documentos únicamente. La práctica fue bastante diversa a lo que la ley disponía."18

\section{Los cabildos en la educación colonial}

Durante el siglo XVIII el Reyno de Chile -a pesar de su posición al sur del Pacífico- fue experimentando profundos cambios ligados con dos fenómenos contradictorios y simultáneos a la vez. En un sentido, las nuevas ideas del racionalismo concedieron ciertos aires de modernidad y efectividad al sistema monárquico y, en otro, la gestación del movimiento cultural al interior de las sociedades despertaron fuertes reflexiones y críticas a sus principios e instituciones. El país seguía una línea de postergación y decadencia con una población no superior a 400.000 personas. ${ }^{19}$

\footnotetext{
15 NICKSON, Andrew. (2005): La descentralización política, en Política y gobierno en América Latina. Crespo, Ismael y A. Martínez, A. (Eds.), pp. 167-199. Valencia, Tirant lo Blanch, p. 169.

16 ALEMPARTE, Julio. (1940): El cabildo en Chile Colonial. Orígenes municipales de las repúblicas hispanoamericanas, Santiago, Ediciones de la Universidad de Chile, p. 37.

17 WEINBERG, Gregorio. (1995): Modelos educativos en la historia de América Latina. Buenos Aires, A•Z editora S.A., UNESCO, CEPAL, PNUD, p. 58.

${ }^{18}$ SÁNCHEZ, Luis. (1972): Historia general de América. 3 Vols. (10 ${ }^{a}$ ed.). Madrid, Ediciones Rodas S. A., p. 449.

19 JOBET, Julio. (1970): Doctrina y praxis de los educadores representativos chilenos. Santiago, Editorial Andrés Bello, p. 104.
} 
Los cabildos, emergidos en el medioevo e introducidos en América fueron las instituciones cívicas más importantes desde los primeros años de advenimiento español, reproduciendo y ajustando la organización de su antecesor peninsular. No fue similar en todas partes, "a partir de un núcleo básico común a la generalidad de los territorios, cada uno desarrolló un modelo acorde con las características y necesidades de su ámbito particular." ${ }^{\prime 20}$ Si bien circulan rasgos de idealización de sus funciones como "representante de una era de oro de la democracia, la realidad era muy distinta." ${ }^{21}$ De hecho, las leyes surgidas en el cabildo requerían confirmación de la península y de la subasta pública de cargos municipales provino su carácter oligárquico. Un aparato de representación de la naciente burguesía local frente a la ancestral burocracia real que encarnaba los intereses de los conquistadores y sus descendientes monopolizando el acceso a la profesión legal, comando militar y clero superior. "Esta tendencia aristocrática perduró hasta los albores del siglo XVII, cuando por la venta de oficios logró el control de la institución capitular un sector con notorio afán de prestigio, progreso social y móviles lucrativos.”22

La composición del cabildo comprendía una base institucional formada por dos alcaldes y seis regidores elegidos anualmente y cargos como el representante de los vecinos, encargado de los caudales y cuentas, secretario de actas, agente del orden público, encargado del estandarte, inspector de suministros, precios y aranceles determinados, funcionario de obras públicas, encargado de anuncios, de convocatoria y de ejecución de justicia. Las funciones eran incontables: distribuían tierras a los ciudadanos, abastecían a la policía local, reclutaban una milicia para proteger la ciudad, sostenían una o más escuelas primarias, inspeccionaban escuelas, maestros y estudios, supervisaban hospitales y médicos, imponían impuestos municipales, administraban justicia en primera instancia, otorgaban permisos de edificación, construían obras públicas, abastecían la localidad, fijaban y vigilaban precios de artículos y servicios, establecían pesos y medidas, registraban actividades que constituían la vida pública y regulaban oficios urbanos.

Cabe mencionar que el presupuesto municipal exhibía la indigencia que en ocasiones no se conmovía con sus despilfarros y más aún, revelaba la indiferencia de los vecinos. Obras de adelantamiento se dilataban por años y aún terminadas, podían sufrir la negligencia por el incumplimiento en el pago de los impuestos. Los datos ofíciales de fines del siglo XVIII mostraban desigualdades que oscilaban de $\$ 9.000$ a $\$ 160$ sobresaliendo las finanzas de la capital, ${ }^{23}$ condición

\footnotetext{
${ }^{20}$ MOLINA. (1996): óp., cit, pp. 53-54.

${ }^{21}$ NICKSON. (2005): óp., cit, p. 169.

22 MOLINA. (1996): óp., cit, p. 75.

23 ALEMPARTE. (1940): óp., cit, p. 84.
} 
vigente y bien hacen historiadores observando la diversidad de recursos y presupuestos y la moderación ante calificaciones y generalizaciones. De hecho, el Cabildo de Santiago no contemplaba recursos para fundar y/o mantener escuelas, sólo el presupuesto de 1798 indicaba entre los gastos fijos los salarios para dos maestros. ${ }^{24}$ A la postre, cuando habían logrado cierta estabilidad y orden legal más permanente, declinaron enfrentados a la burocracia real asociada a poderes superiores y menoscabo de rangos- y a la venta o remate de cargos municipales a perpetuidad.

La incipiente escuela pública, -subordinada a la asamblea de la comunidadconsiderada desde la elaboración de los planos de un pueblo, en su procedimiento, sólo satisfacía a un sector y era usualmente desplazada a las órdenes religiosas. Para algunos historiadores, la monarquía rechazaba la cuestión educativa porque podía ser fuente de perniciosas consecuencias, incluso de rebeliones frente al poder imperante y para otros, constituía una obra de caridad que debía ser asumida por la Iglesia. Los diversos y discontinuos esfuerzos mostraron una contradictoria legislación educativa y una permanente escasez de medios económicos para mantener las escuelas. El período "deja en descubierto la pobreza increíble de los recursos disponibles para la difusión de la instrucción pública en la época colonial.”25 De todos modos, las escuelas debían administrarse por el gobernador provincial o alcalde a través de un fondo nacional y los donativos de algunos vecinos. El cabildo asignaría un porcentaje de sus ingresos al sostenimiento de la enseñanza y una parte de sus impuestos a los salarios de los maestros.

La enseñanza colonial impartida en conventos atendía a niños y jóvenes de una pequeña minoría social. Las niñas de familias acomodadas tenían alguna educación en congregaciones de religiosas circunscrita a prácticas religiosas. En forma paralela, excluía a sectores por diferencias sociales, étnicas, económicas o de género. Los centros no diferenciaban funciones ni enseñanzas, existían tres tipos: las escuelas de primeras letras eran pocas y mal mantenidas, la mayoría a cargo de frailes y algunas de iniciativa del cabildo contaban con un maestro que inculcaba doctrina cristiana, lectura, escritura y nociones de aritmética y de latín. Las escuelas de gramática y latinidad que iniciaba a niños y adolescentes en los rudimentos del latín. Los convictorios o seminarios y universidades pontificias insistían en religiosidad, latín, nociones abstractas y prejuicios históricos, sin ninguna relación con los problemas de la sociedad. Estos últimos constituían estudios superiores y la universidad formaba teólogos, filósofos y grandes predicadores. ${ }^{26}$

\footnotetext{
${ }^{24}$ Ibídem, p. 85.

25 JOBET. (1970): óp., cit, p. 113.

${ }^{26}$ LABARCA. (1939): óp., cit, pp. 28-30.
} 
En todos los ámbitos de la vida colonial existió un fuerte predominio religioso. "La iglesia católica era un elemento obligado de la vida en los tiempos coloniales, al menos en las ciudades (...) jugaba un papel activo en la educación." ${ }^{27}$ Una política que facultaba aún más a las órdenes religiosas consideraba que todo religioso tenía derecho a enseñar, en cambio, los maestros laicos debían cumplir con preceptos derivados de la autoridad eclesiástica y del cabildo para ingresar al oficio: buena vida y costumbres; limpieza de sangre; convicción católica y prueba de conocimientos. "En realidad, se consideraba al magisterio como un oficio esencialmente religioso, en el sentido que era la iglesia el poder docente y no el Estado." ${ }^{28}$ De esta forma, la enseñanza colonial subsistió estigmatizada, "una pobre educación, avasallada por las prácticas religiosas, repleta de filosofía escolástica y teología, con mal latín, y sin estudio del idioma patrio y de las ciencias (...) descuidada en su funcionamiento regular." ${ }^{29}$

La generalidad de argumentos de privación educativa revela una crítica recurrente al régimen monárquico: "la España absolutista ignoró la necesidad de una enseñanza primaria extensa en la metrópolis y la escatimó avaramente en las colonias." ${ }^{30}$ Pero tales carencias no eran deliberadas, eran equivalentes a la situación que vivía la península, "se le enrostra (...) no haber fundado tantas escuelas como conventos. El hecho es exacto, pero la acusación no tanto. España tampoco disponía para su consumo, en su propio territorio, de las escuelas que los americanos hubiesen querido para sí." ${ }^{31}$

A pesar del largo derrotero y de incontables obstáculos, se fundaron dos centros patrocinados parcialmente por el cabildo. La Academia de San Luis, "especie de instituto técnico,"32 inició sus actividades el año 1797 liderado por Manuel de Salas para fomentar la industria, el comercio y los oficios incorporando nuevas disciplinas en la enseñanza. La Universidad en 1713 procedió de los reclamos de los vecinos convocados en el Cabildo de Santiago del Nuevo Extremo. La autorización de la Universidad de San Felipe data de 1738 y su fundación, -veinticinco años después- pone a la vista "la velocidad de las tramitaciones burocráticas. Pero sus actividades sólo comenzaron en 1756, con diez cátedras." 33

\footnotetext{
27 DE RAMÓN, Armando. (2001): Breve historia de Chile. Desde la invasión incaica hasta nuestros días (1500-2000). Buenos Aires, Editorial Biblos, p. 31

${ }^{28}$ LABARCA. (1939): óp., cit, p. 31.

29 JOBET. (1970): óp., cit, p. 121.

${ }^{30}$ LABARCA. (1939): óp., cit, p. 71.

31 SÁNCHEZ. (1972): óp., cit, p. 475.

32 ALEMPARTE. (1940): óp., cit, p. 272.

33 WEINBERG. (1995): óp., cit, p. 74.
} 
A estas alturas, en la institución edilicia "residía el manejo de la vida cotidiana de la ciudad y sus miembros tenían la posibilidad de orientar la política de desarrollo local de forma que les beneficiase personal o familiarmente mediante prerrogativas o concesiones de todo tipo." 34 Su estructura y funcionalidad privilegiaba verticalismo y distribución hacia el exterior y con ella, el deterioro del progreso local. Había más, la participación no era equitativa, representaba una parte de la economía local. Tantos incidentes unidos a las arbitrariedades laborales, originaron y reforzaron la desigualdad al interior de la comunidad. $\mathrm{Al}$ surgir la crisis monárquica, los cabildos no distaron de sus normas tradicionales, no se inclinaron hacia acciones uniformes y organizadas, no unieron fortalezas para incrementar sus acciones. Las autoridades locales utilizaron la oposición entre sectores que padecían tensiones y problemas. Por tanto, el montaje del Estado fue "lento (tardó casi medio siglo), zigzagueante (fue tironeado por los estallidos laterales de su conflicto interno) y distorsionado (no triunfó la legitimidad cívica sino la ?idea' oligárquica)." ${ }^{35}$

Durante los años de emancipación, la educación no estuvo exenta de conflictos, de lentos avances y diversos retrocesos. Las manos de congregaciones siguieron atendiendo a los hijos de funcionarios, capitanes, hacendados o mercaderes ${ }^{36}$ suscitando desconfianza y rechazo de los nuevos gobernantes.

\section{Las obligaciones municipales con la educación local}

A comienzos del siglo XIX la población del país se calculaba en medio millón de habitantes. ${ }^{37}$ Los acontecimientos en Francia y Estados Unidos repercutieron en Chile y sobre su régimen colonial que ya exhibía contradicciones, inmovilismo y disconformidad. Las nuevas ideas difundidas conducían -a través de la educación del pueblo- a las "luces, razón, soberanía popular, felicidad y productividad." 38 En 1810 sobrevino una inaugural y moderada independencia del Reino de España, ligada a un ambiente de disidencia y disputa del poder protagonizada por dos bandos en torno al cabildo, unos patrocinando derechos para decidir por sí mismo y otros partidarios de mantener el sistema colonial. ${ }^{39}$

Los planes de la primera Junta de Gobierno, derivados de un cabildo abierto -única institución capaz de avanzar hacia un gobierno provisional- con notables

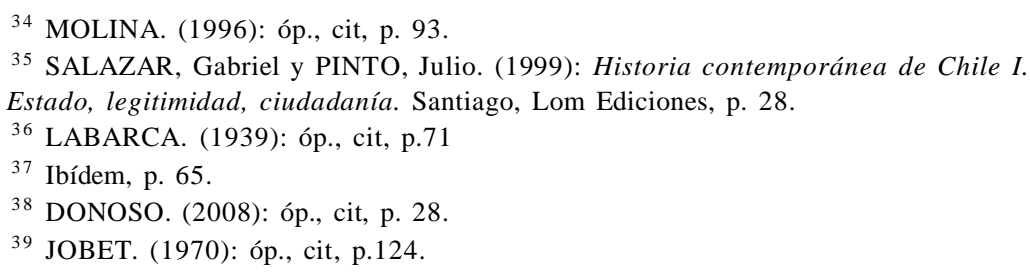


convocados, aseguraron el predominio de las elites criollas ${ }^{40}$ y el camino hacia la emancipación. "En ellos la voluntad popular tuvo por vez primera conciencia de sí misma, y en los cabildos abiertos el pueblo hizo sus primeros ensayos de gobierno propio." ${ }^{41}$ Esta imagen, generalmente positiva, de los cabildos coloniales en América Latina tuvo directa relación con el protagonismo emprendido en la guerra por la independencia. ${ }^{42}$ Mas, cabe complementar que en manos de la oligarquía, implicaba no sólo "organizar las instituciones que regirían el futuro Estado sino en cómo mantener el control de éste y cómo reacomodar las estructuras sociales y económicas que se habían heredado." ${ }^{43}$

El resultado, una sucesión de gobiernos patriotas centrados en la creencia que sólo una carta fundamental garantizaría el progreso del país. Simultáneamente, éstos debieron enfrentar "los vaivenes de las luchas armadas para consolidar la emancipación, con sus flujos y reflujos," 44 endureciendo las posiciones oligárquicas y las ideas revolucionarias. Por derivación "la falta de plan constructivo y la sobra de individualismo" dieron paso a los estragos de las confrontaciones civiles. Dichos próceres, transformados en políticos -más idealistas que experimentados- no dejaron descansar la espada, profundizando las diferencias vistieron propósitos personales, hizo presencia el caudillaje local y conjuntamente, las definiciones nacionales. ${ }^{45}$

La preocupación por la cultura y la educación de la población estuvo presente en la acción emancipadora, ${ }^{46}$ "se produjo una verdadera ola de optimismo pedagógico en las nuevas naciones." ${ }^{47}$ Sin embargo, "la educación se plantea principalmente en relación con sus funciones políticas, y sólo en grado muy inferior en cuanto a su papel instrumental." ${ }^{48}$ La educación se juzgaba indispensable en el proyecto de transformación política, para asentar la vida republicana, crear ciudadanos, enseñar valores y educar la inteligencia. "Los pensadores y políticos locales reclamaban para sus pueblos la educación que

${ }^{40}$ HALPERIN. (1972): óp., cit, p. 91.

${ }^{41}$ HARING. (1972): óp., cit, p. 178.

${ }^{42}$ NICKSON. (2005): óp., cit, p. 169.

${ }^{43}$ DE RAMON. (2001): óp., cit, p. 66.

${ }^{44}$ WEINBERG. (1995): óp., cit, p. 123.

45 SÁNCHEZ. (1972): óp., cit, p. 665.

${ }^{46}$ EGAÑA, Loreto. (2000): La educación primaria popular en el siglo XIX en Chile: Una práctica de política estatal. Santiago, DIBAM, PIIE, LOM, Centro de Investigaciones Diego Barros Arana, p. 26.

47 NEWLAND, Carlos. (1991): La educación elemental en Hispanoamérica: Desde la independencia hasta la centralización de los sistemas educativos nacionales. The Hispanic American Historical Review, 71, (2), p. 337.

${ }^{48}$ RAMA, Germán. (1987): Educación y Sociedad en América Latina. Revista Interamericana de Desarrollo Educativo. Washington, OEA, Vol. XXXI, I y II, p. 47. 
los libraría de la ignorancia impuesta por los españoles." 49 Hubo producción de leyes y decretos educativos pero falta de aplicación y cumplimiento debido a las continuas embestidas opositoras amenazando la autonomía, las limitadas condiciones educativas heredadas, las debilidades del erario, el individualismo asociado a la continuidad de privilegios, la desorganización administrativa y la no menos importante, inexperiencia de los propios dirigentes.

En forma concreta, voluntades y esfuerzos viraron al proceso de construcción del Estado sobre la base de dos condiciones mínimas: la instauración de un ejército nacional y de una administración elemental. Paralelamente, se excluyeron del poder y de las decisiones políticas a los sectores populares de la $\operatorname{sociedad}^{50}$ y para este último, este fenómeno explicaría en algún sentido las frágiles prioridades atribuidas a la educación. De todos modos, en la redefinición de fuerzas o de control político (liberales y conservadores) se incorporaron rasgos cívicos y debate de intereses, prejuicios y valores sobre la educación que demandaba el país.

En 1812 J. M. Carrera "exigió a los cabildos y a los conventos abrir escuelas primarias y ordenó que cada monasterio de religiosas destinara una sala para dar enseñanza a las niñas." ${ }^{51}$ "Su financiamiento por medio de recursos locales [dañado por el conflicto independista] hacía que su número y calidad estuviera relacionado con la riqueza o pobreza de la comunidad." 52 Ese mismo año -en el primer censo escolar del país- se solicitaba al Cabildo de Santiago instalar escuelas en lugares determinados, designar maestros, observar las escuelas de los conventos, costear la impresión de mil cartillas y catones para distribuirlos entre los niños más pobres y nombrar un "regidor protector de las escuelas" para visitarlas mensualmente. ${ }^{53}$

$\mathrm{Al}$ año siguiente la Junta de Gobierno reglamentó ${ }^{54}$ orientaciones para la enseñanza primaria fundadas en la misión educacional del Estado. Asimismo, el Plan de Constitución establecía el cuidado de la educación pública como primera medida de pacto social. ${ }^{55}$ En medio de enormes limitaciones, de una

\footnotetext{
${ }^{49}$ NEWLAND. (1991): óp., cit, p. 337.

${ }^{50}$ RAMA. (1987): óp., cit, p. 47; WEINBERG. (1995): óp., cit, p. 123.

51 JOBET. (1970): óp., cit, p. 130.

52 NEWLAND. (1991): óp., cit, p. 346.

${ }^{53}$ CHILE, AURORA DE CHILE. (1812, Diciembre 17). Tomo I, No 45, p. 191. Consultado el 30/05/2009 en: http://www.auroradechile.cl/newtenberg/681/article3157.html

${ }^{54}$ El Reglamento para maestros de primeras letras impulsaba la educación popular proponiendo la apertura de una escuela gratuita para niños y otra para niñas en cada pueblo con más de 50 habitantes, los textos que se utilizarían, la importancia de los maestros, el servicio que brindarían a la patria y la mantención del sistema escolar a través de los cabildos.

${ }^{55}$ LABARCA. (1939): óp., cit, p. 76.
} 
independencia ceñida de peligros y debilidades, y de la indigencia para llevar a cabo cualquier proyecto, se refundieron antiguas instituciones inaugurándose el Instituto de Educación e Industria Popular. Las iniciativas educacionales, una vez más, sufrieron detenciones porque los cambios políticos y la reconquista española en 1814 abrieron un paréntesis de resistencia y sometimiento.

En 1817 B. O’Higgins “dedicó loables esfuerzos al desarrollo de la educación. Dictó nuevos decretos y reglamentos sobre promoción y régimen de las escuelas públicas; protegió la instauración del sistema lancasteriano." ${ }^{56}$ Asimismo creó la figura del "protector de la enseñanza primaria, una especie de Director General" 57 y atribuyó a los 21 cabildos existentes ${ }^{58}$ la creación, el sostenimiento y la fiscalización de las escuelas de su comunidad. Ese año se recuperó definitivamente la soberanía del país. Entre 1817 y 1819 se reiniciaron las actividades del Instituto, se creó la Biblioteca Nacional, la Academia Militar y la Academia de Guardiamarina, signos elocuentes de que el impulso reformador no declinaba.

La guerra de independencia produjo un antes y un después en los países hispanoamericanos, "su inesperada duración, la transformación que había obrado en el rumbo de la revolución, [ampliando sus bases y las del sector contrarrevolucionario] parecía la causa más evidente de esa escandalosa diferencia entre el futuro previsto en 1810 y la sombría realidad de 1825." ${ }^{59}$ Proclamada la independencia chilena en 1818 se inició un ciclo no liberado de beligerancia e inestabilidad política. En otras palabras, resuelta la dependencia externa, se abrió el conflicto de las dependencias internas. "La polarización 'abstracta' entre patriotas y realistas dejó paso a la polarización más concreta entre 'pelucones' y 'pipiolos', y entre 'centralistas' y 'federalistas'. La autonomía comenzó a lucharse al interior de cada comunidad, como un conflicto cívico verdaderamente 'republicano'." ${ }^{60}$ Estas circunstancias explicarían un número importante de años en los que Chile pasó de un experimento a otro en la esfera política, ${ }^{61}$ en la

\footnotetext{
56 JOBET. (1970): óp., cit, p. 146.

57 CAMPOS. (1960): óp., cit, p. 14.

${ }^{58}$ CHILE. MINISTERIO DEL INTERIOR. (2006). 2000-2006 Memoria de la descentralización. Santiago, SUBDERE, p. 21.

${ }^{59}$ HALPERIN. (1972): óp., cit, p. 129.

${ }^{60}$ SALAZAR y PINTO. (1999): óp., cit, p. 31.

${ }^{61}$ Diversidad de gobiernos ensayaron ordenanzas y regulaciones de convivencia a través de la formulación de distintos textos constitucionales. Liberales o pipiolos presentaban un proyecto claramente republicano que protegía y fomentaba la producción, privilegiaba la autonomía local sobre la central y promovía la elección democrática de los poderes públicos. Sus opositores, conservadores o pelucones patrocinaban un programa con características más abiertas que locales que no llegaba a unir las necesidades de la mayoría ciudadana, el sector estaba compuesto por mercaderes con fortuna que habían adquirido títulos y cargos, militares autoritarios y defensores de la monarquía.
} 
búsqueda de su propia organización o en la "lucha por la organización del Estado."62 Bajo otra mirada, "una vez disipada la euforia de la independencia, los gobiernos locales quedaron ahogados bajo el control de los nacientes Estados-nación, cuyos dirigentes invariablemente replicaban la tradición centralista y elitista de sus antecesores coloniales." 63

Con todo, la mayoría de los intentos de estructura y organización estatal no prescindieron de la obligación de los cabildos con la educación. El Proyecto de Constitución de 1818 señalaba que deberían fomentar el adelantamiento de la población y entre éstos, la educación de los jóvenes. ${ }^{64}$ En 1822 se promulgó una nueva carta fundamental, ${ }^{65}$ que a pesar de su corta duración distinguía dos tendencias de administración educacional: la uniformidad del centro y la delegación en cabildos y conventos como su correspondiente observancia. Otra tentativa al año siguiente creaba el Consejo de Estado que en sus secciones incluía la instrucción pública, moralidad, servicios, mérito nacional y negocios eclesiásticos ${ }^{66}$-futuro ministerio del ramo- y la supervisión encomendada al senado. ${ }^{67}$ Además, un Consejo Departamental debía velar sobre la instrucción pública y el municipio cuidar y atender a todos los objetos encargados a éste. ${ }^{68}$ La descentralización develó la dualidad de responsabilidades que subsistieron en el ejercicio de los agentes de supervisión.

Entre 1825 y 1827 se propuso una Constitución Federalista -obstruida y rechazada- que asentaba la elección popular en las provincias y en los cabildos, donde cada provincia tendría una asamblea de elección popular con carácter legislativo. El gobierno transitorio de 1828 promulgó un texto constitucional que exponía los compromisos educacionales de los municipios: "establecer, cuidar y proteger las escuelas de primeras letras, y la educación pública en todos sus ramos." 69 Si bien comprende obligaciones que no implicaban ampliar

\footnotetext{
${ }^{62}$ CAMPOS, Fernando. (1960): Desarrollo educacional 1810 -1960, Santiago, Editorial Andrés Bello, p. 15.

${ }^{63}$ NICKSON. (2005): óp., cit, p. 170.

${ }^{64}$ CHILE, PROYECTO DE CONSTITUCIÓN PROVISORIA PARA EL ESTADO DE CHILE. (1818). Biblioteca del Congreso Nacional, [en línea], p. 9. Consultada el 26/05/ 2009 en: http://www.bcn.cl

${ }^{65}$ CHILE, CONSTITUCIÓN POLÍTICA DEL ESTADO DE CHILE. (1822). Biblioteca del Congreso Nacional, [en línea], p. 21. Consultada el 26/05/2009 en: http://www.bcn.cl ${ }^{66}$ CHILE, CONSTITUCIÓN POLÍTICA DEL ESTADO DE CHILE. (1823). Biblioteca del Congreso Nacional, [en línea], p. 4. Consultada el 26/05/2009 en: http://www.bcn.cl

${ }^{67}$ Ibídem, p. 6.

${ }^{68}$ Ibídem, p. 17.

${ }^{69}$ CHILE, MINISTERIO DEL INTERIOR. (1828). Constitución Política de la República de Chile 1828. Santiago, Imprenta de R. Rengifo, p.21. Consultado el 20/12/2009 en: http://www.memoriachilena.cl/archivos2/pdfs/MC0019511.pdf
} 
oportunidades a los menos favorecidos, en la práctica, todos los municipios -excluyendo Santiago- enfrentaron la insuficiencia de fondos para desarrollar las tareas asignadas.

Desde esta perspectiva, "la oligarquía chilena nunca tuvo una política social estructurada como para dar solución a los graves problemas que sufría la población pobre del país." "70 La tendencia revelaba una abierta incapacidad y/ o indiferencia instrumental del gobierno para responsabilizarse directamente la enseñanza, en tal caso, su estrategia consistía en desplazar total o parcialmente la gestión a otras entidades, como el cabildo, la iglesia y particulares.

Es importante resaltar que la construcción del Estado bajo un modelo centralizado se acompañó de un constante proceso de expropiación y cercenamiento del aparato local. En él, se transfería la autonomía y el poder comunal al contexto nacional y casi en la misma medida, se fortalecían los poderes centrales de la clase política dominante. De hecho, el gobierno local fue por completo suprimido entre 1830 y 1861 . $^{71}$ "Disuelto el lazo (poder) vecinal, el Estado tendió (sobre todo en Chile) a ser construido y reconstruido, ya no desde células matrices, ni desde el poder soberano (la masa ciudadana que vive en comunidad), sino desde abstracciones políticas y desde la 'fuerza', o la "violencia." 72

En este encadenamiento, el cabildo, -posteriormente llamado municipio o municipalidad- va descendiendo a un estado de incapacidad, marginación e inercia, situación generalizada a todos los servicios municipales y, por ende, a la educación local. También es cierto que hubo un grupo de comunidades que se rebelaron frente esta degradación, pero sucumbieron debido a la fuerza del autoritarismo y centralismo gubernamental vigente.

\section{El contraste de los ingresos fiscales y municipales}

Las casi dos décadas de ensayos políticos y constitucionales cesaron en 1830 tras la imposición del proyecto liderado por D. Portales. Es tiempo de expansión minera, presencia inglesa y complejidad social; por un lado, introdujo circulación monetaria que favoreció a la población rural y por otro, oprimió a sectores sociales continuamente desfavorecidos.

\footnotetext{
70 DE RAMÓN. (2001): óp., cit, p. 105.

71 NICKSON. (2005): óp., cit, p. 170. Existió un lapso vacío, un período entre 1817

y 1854 de absoluto silencio gubernamental y legal (excepto la frustrada propuesta federalista de 1826), sin aprobación de ninguna ley orgánica que acreditara la organización de los cabildos dentro del aparato estatal, sólo algunas normas constitucionales.

72 SALAZAR y PINTO. (1999): óp., cit, p. 265.
} 
Una de las primeras medidas educacionales fue la devolución de los bienes raíces a las órdenes religiosas, -retenidos en 1824- subordinadas a que abrieran una escuela de primeras letras en cada pueblo donde mantuvieran casa conventual. Sin respuesta, en 1832 la norma fue reiterada con carácter de obligatoriedad, de lo contrario las municipalidades fundarían las escuelas a cuenta de los conventos. Esta vez hubo respuestas pero las escuelas funcionaron en recintos inapropiados, a cargo de un ayudante y sin materiales. Más un reducido programa de estudios que contenía doctrina cristiana, lectura, escritura, cuatro operaciones de aritmética, moral y urbanidad. ${ }^{73} \mathrm{El}$ gobierno se reservaba sólo la protección superior administrativa y el derecho de fijar las orientaciones generales a la enseñanza primaria. No se resolvía aún si el Estado debía o no intervenir directamente en la educación. A pesar de ello, se ayudaba con exiguos fondos a las escuelas secundarias de estudiantes de clase privilegiada. Las escuelas primarias bajo la responsabilidad de cabildos y conventos eran el modelo heredado de la Colonia que la alianza conservadora mantenía por su oposición de masificar la enseñanza a toda la población.

El gobierno de J. J. Prieto promulgó la Constitución Política de 1833 organizando un Estado en correspondencia con las voluntades oligárquicas, -sin atribuciones de perfección- impuso en una orientación el orden, la obediencia y la sumisión de la sociedad civil, y en otra, la estabilidad política, el despotismo y proteccionismo económico. En el capítulo de las municipalidades declaraba nuevamente su nexo con la educación local: "Cuidar de las escuelas primarias i (sic) demás establecimientos de educación que se paguen de fondos municipales". ${ }^{74}$ Más adelante, que la educación pública sería de atención preferente del gobierno, la formación de un plan general de educación nacional, la cuenta anual del ministro y de la inspección situada en una superintendencia. ${ }^{75}$ De cara al texto constitucional, todas las políticas basadas en el enfoque social constituían especial y principal preocupación del Estado, una primera inclinación al Estado Docente. ${ }^{76}$ Por cierto, sólo a partir de 1835 la Ley de Presupuesto contempló aspectos referidos a la instrucción y a la enseñanza primaria. ${ }^{77}$ Aunque los municipios conservaron sus obligaciones con la educación de su territorio, la administración central empezó a ganar presencia en la educación, de hecho, las escuelas se dividieron en "escuelas municipales, escuelas

\footnotetext{
${ }^{73}$ LABARCA. (1939): óp., cit, p. 88.

${ }^{74}$ CHILE, MINISTERIO DEL INTERIOR. (1833). Constitución Política de la República de Chile 1833. Santiago, Imprenta de la Opinión, p. 38. Consultado el 20/12/2009 en: http://www.memoriachilena.cl/archivos2/pdfs/MC0003673.pdf

${ }^{75}$ Ibídem, pp. 43-44.

${ }^{76}$ El proceso de estatización educacional en Chile se denomina Estado Docente.

${ }^{77}$ LABARCA. (1939): óp., cit, p. 88.
}

Rev. hist. edu. latinoam. Vol. 15. Año 2010, pp. 93 - 124 
sostenidas por el Erario Nacional y escuelas conventuales sostenidas por órdenes religiosas." 78

Desde otro aspecto, -arrasó con los poderes locales- las comunidades provinciales y locales con representantes elegidos popularmente fueron reemplazadas por un gobierno superior en cada provincia y en todos los niveles administrativos, en el cual residiría un Intendente de acuerdo a las leyes y a las órdenes del Ejecutivo. ${ }^{79}$ Atrás quedaron las asambleas provinciales de 1828 inspiradas en el federalismo. Las Intendencias Provinciales (designadas por el presidente) actuaban en muchos sentidos como enlace con la administración local. Los intendentes y sus subdelegados y gobernadores tenían poderes de veto absoluto sobre los consejos municipales elegidos. Por ende, la hegemonía de Santiago se vio reforzada a costa de la iniciativa local.

En 1837 se crea el Ministerio de Justicia, Culto e Instrucción separándose del Ministerio de Interior. A éste cabía la promoción y el funcionamiento de los establecimientos educacionales con fondos nacionales o municipales. La política educativa emergente consistió en fundar escuelas "fiscales" carecían de ellas. En las estadísticas de 1841 figuraban 54 escuelas fiscales con un presupuesto de $\$ 10.750 .{ }^{81}$ La educación mantenía problemáticas derivadas de las postergaciones precedentes: calidad de la enseñanza, medios disponibles e instrucción seguían siendo muy insuficiente.

Las exploraciones pedagógicas continuaron en la segunda y tercera década y se materializaron después de 1840 con resultados paulatinos en el incremento de la enseñanza primaria, el fortalecimiento de la segunda enseñanza, la promoción de la educación femenina y el diseño de una estructura administrativa centralizada y unitaria. Políticos, intelectuales y maestros de la época -Montt, Bello, Lastarria, Sarmiento y Varas- convenían con que el Estado debía procurar educación a todos los ciudadanos, organizando y financiando instituciones para ello. Un enfoque republicano de formación para vivir al interior de un nuevo modelo político, económico, social y cultural. De esta forma, se creó cierto consenso sobre la educación en cada uno de los niveles: primario, secundario y universitario. Hubo énfasis en la extensión del sistema, especialmente en las escuelas primarias. "El efecto es notorio en el aumento de la matrícula de ese nivel, pues en 1854 llega a 27.449 alumnos; en 1860 a 43.368; en 1865 llega a 51.294." ${ }^{\prime 2}$

\footnotetext{
78 CAMPOS. (1960): óp., cit, p. 17.

${ }^{79}$ MONTECINOS. (2005): Antecedentes sobre la relación histórica centralismo y descentralización en Chile, en Revista Venezolana de Gerencia, 31, Venezuela, pp. 449-450.

${ }^{80}$ Se refiere a establecimientos educacionales costeados por el erario nacional, en Chile

es sinónimo de estatal y público.

${ }^{81}$ CAMPOS. (1960): óp., cit, p. 61.

${ }^{82}$ Ibídem, p. 61.
} 
Posteriormente se debatió respecto de la preocupación en la enseñanza primaria o superior. Una argumentaba que no era posible crear universidades en el aire sin tener un sistema educacional primario y secundario que las sustentara y otra, que era imposible crear escuelas primarias sin profesores, ni textos, ni métodos, ni una doctrina educacional adecuada. La solución política mantuvo la histórica protección de las capas superiores de la estructura social y más tarde, los estratos inferiores, coincidiendo con una organización del sistema de enseñanza de arriba hacia abajo. ${ }^{83}$

La presidencia de M. Bulnes impulsó la organización del sistema educativo fundando en 1842 la Escuela Normal de Preceptores bajo la tenaz iniciativa de Sarmiento y en 1843 la Universidad de Chile a cargo de la sólida formación de Bello, delegando a esta última, la Superintendencia de la educación pública en todos sus grados. La Facultad de Filosofía y Humanidades dirigió la enseñanza primaria hasta 1860 y la secundaria hasta 1927. La educación primaria fue asumida en los aspectos operativos por el ministerio y en los pedagógicos por la universidad. "El primero se encargó de la fundación y la dotación de las escuelas, la segunda de la revisión de textos y reglamentos, asignación de premios a preceptores y supervisión de la marcha de las escuelas." 84

Desde entonces, la legislación de la enseñanza, los programas de estudios, la duración de los cursos y las normas de promoción emanaron de autoridades públicas. Las tareas de inspección y el control en los exámenes fueron prácticas obligadas de intervención estatal. La enseñanza particular disfrutaba de protección, debido posiblemente a un Estado carente de competencias y a gobiernos protectores de la libertad de enseñanza.

En 1843 salió a la luz el primer proyecto de ley de educación ${ }^{85}$ presentado al Congreso. Sin embargo, distintas versiones sufrieron el largo peregrinaje de modificaciones y observaciones en su trámite legislativo y en el peor de los casos, desacertadas postergaciones. En efecto, un modo de financiación discutido en 1850 creaba un impuesto directo de todos los ciudadanos "y cuyo producto sería recaudado y administrado por la Municipalidad de cada departamento. Estos signos de descentralización consignados en el proyecto iban a desaparecer en la ley." ${ }^{\circ 6}$ Políticos y educacionistas debatieron en torno a la promoción de

\footnotetext{
${ }^{83}$ Rama señala que el modelo oligárquico estaba interesado en la educación de su propio grupo, manteniendo o creando universidades para formar abogados y teólogos, los primeros regirían las sociedades y los segundos sustentarían los valores, p. 47.

${ }^{84}$ EGAÑA. (2000): óp., cit, p. 49.

${ }^{85}$ Sobre los procesos que siguieron los proyectos de ley ver en LABARCA (1939); CAMPOS (1960); MONSALVE (1998) y EGAÑA (2000).

${ }^{86}$ CAMPOS. (1960): óp., cit, p. 23.
} 
un sistema de instrucción para el pueblo. ${ }^{87}$ En 1857 se restableció el proyecto de ley y la discusión sobre cobertura y financiamiento educativo, ingerencia de la Iglesia y rol de las municipalidades. Una de las líneas situaba a la escuela parte esencial del patrimonio local y a los municipios autónomos para administrar recursos anuales que recibirían del gobierno central en directo beneficio de la instrucción primaria en su territorio, pero la réplica del Ministro del Interior de la época no se hizo esperar y fue concluyente:

Yo veo la cuestión bajo un punto de vista mui (sic) diverso: le doi (sic) muchísima importancia i (sic) creo que es el gobierno quien debe intervenir con preferencia (...) No es posible dejar asunto tan importante a la solicitud cuidado de las Municipalidades i (sic) de los particulares; esta confianza me parece perniciosa i (sic) de fatales consecuencias para el país. Si asílo hiciésemos ¿que sucedería, cuando se oye por todas partes $i$ (sic) aún a individuos de la Cámara misma, la instrucción primaria ha traído más males que bienes? ¿Que en los campos se ha hecho sentir especialmente el perjuicio que ha producido la instrucción primaria? ${ }^{88}$

La política educativa impulsó la educación fiscal, la expansión de la enseñanza primaria y en paralelo, reafirmó su carácter centralista. Por lo demás, ciertas medidas menoscabaron los servicios que solían prestar los municipios como la pérdida de autonomía. "Las normativas de la Constitución de 1833 establecieron, pues, las bases para que una cartografía política de control central sustituyera la cartografía natural de las comunidades." 89 Las responsabilidades municipales en economía, salud, educación, obras públicas, seguridad y beneficencia, entre otras, quedaron sin espacios de libertad y su ejecución bajo instructivos del gobierno central. Desde otros ámbitos, los poderes centrales fueron perfeccionando los mecanismos de invasión y expoliación, y por consecuencia, ampliando la miseria en las provincias.

Los recursos fiscales crecieron como resultado de la explotación minera -del trabajo realizado en las provincias- de plata, cobre y salitre. El Estado empezó a percibirse como único gran inversionista capaz de solucionar todos los problemas sociales y económicos y, absolutamente descartados una posible coparticipación y/o autogestión municipal. Esta idea más la condición de país monoproductor estigmatizó por vía electoral considerar impuestos locales para financiación municipal. Todos estos factores explicarían el aumento del ingreso fiscal en detrimento del ingreso municipal y sus efectos en la gestión de las municipalidades.

\footnotetext{
${ }^{87}$ En este período no se excluyeron las cuestiones referidas a las responsabilidades del municipio y del Ministerio de Justicia, Culto e Instrucción.

${ }^{88}$ EGAÑA. (2000): óp., cit, p.56.

${ }^{89}$ SALAZAR y PINTO. (1999): óp., cit, p. 271.
} 


\section{Las municipalidades frente a la estatización}

La ley de educación de 1860 -vigente por más de 50 años- no era muy distinta a la versión del proyecto de ley presentado en 1849, la diferenciación era su espíritu, "era esencialmente centralista." ${ }^{90}$ El financiamiento "provenía de fondos municipales, mandas forzosas, aportes estatales y de una contribución, la que sería reglamentada por una ley especial que se dictaría posteriormente, lo cual nunca ocurrió." ${ }_{91}$ Asimismo, confirmó la gratuidad de la enseñanza primaria y traspasó este nivel a la dirección del Gobierno, -Ministerio de Justicia, Culto e Instrucción Pública- y no de la Universidad de Chile ${ }^{92}$ y formalizó un sistema escolar mixto administrativa y financieramente, consagrándose coparticipación entre un régimen nacional y uno municipalizado.

En el ámbito administrativo disponía fundar escuelas en relación al número de habitantes por departamentos y de escuelas normales, creaba una Inspectoría y la figura del visitador para vigilar y dirigir la instrucción primaria. Los municipios podían nombrar comisiones con el mismo propósito, pero las prescripciones de la Inspección General eran inmodificables. En el aspecto financiero establecía diversos fondos: una suma anual del tesoro nacional, una de las propias rentas municipales derivada de fundaciones, donaciones y multas aplicadas a la instrucción primaria en cada departamento y una contribución fijada por ley de forma general y especial en cada departamento. Los municipios presentarían al Ejecutivo el presupuesto requerido anualmente en la instrucción primaria para su aprobación, previa a eventuales las modificaciones. ${ }^{93}$

Tras la anulación de los órganos políticos de representación, como era el Cabildo en 1833, los grupos locales reaccionaron creando otras instancias de asociación abierta y deliberante al interior de algunas comunidades, aunque dispersas, todas con el firme propósito de restablecer el gobierno comunal con fueros y autonomía. A pesar que interpretaron las reivindicaciones regionales y locales como "un nuevo orden político constitucional, una nación federal," ${ }^{44}$ no

\footnotetext{
${ }^{90}$ CAMPOS. (1940): óp., cit, p.26.

${ }^{91}$ EGAÑA. (2000): óp., cit, p. 57.

92 Otras medidas se dirigían a la fundación de escuelas superiores, una de hombres y una de mujeres, por cada 2000 habitantes en cada cabecera de departamento. Además, insistía en la apertura de una escuela gratuita en todos los conventos y diferenciaba entre escuelas elementales y superiores. La enseñanza privada también quedaba a cargo de la inspección del Estado, aunque sólo en materias relativas a la moralidad y el orden.

${ }^{93}$ CHILE. MINISTERIO DE INSTRUCCIÓN PÚBliCA. (1863). "Normas Reglamentarias para aplicar la Lei de Instrucción Primaria de 1860 del 1 de diciembre de 1863," en: Boletín de las Leyes y Decretos del Gobierno, Santiago, Ministerio de Instrucción Pública, pp. 371-394.

${ }^{94}$ MONTECINOS. (2005): óp., cit, p. 451.
} 
contaron con medios formales de expresión y presión; el único camino viable fue el levantamiento local, consignado durante las guerras civiles de 1851, 1852 y 1859. La masa comunal fue subyugada por el círculo gobiernista que envolvía el territorio local, grupo minoritario compuesto por intendentes, gobernadores, subdelegados, inspectores, empleados fiscales, la mayoría oriundo de otras regiones. No acabó ahí, un nuevo incidente silenció al movimiento comunalista. La estrategia gubernamental dividió las comunidades locales, aceptando la incorporación de sus líderes liberales y partidos en el gobierno central, segmento que aportó las bases locales de apoyo "democrático" a conservadores y liberales. ${ }^{95}$

Si bien las entidades populares quedaron aisladas, se reunieron nuevamente reorientando sus posibilidades de soberanía y de política de oposición. Uno de los resultados del movimiento -tras muchos años- fue la Ley de Municipalidades en 1854. Evidentemente, sus normas no se diferenciaban de las ordenanzas municipales de la Constitución de 1833, -eran responsables directos de las políticas sociales (incluyendo la educación de su territorio) y del fomento de la producción- salvo la excesiva asignación de facultades y deberes con presupuesto insuficiente para hacer gestión. ${ }^{96}$

La legislación puede interpretarse porque la política imperante promovía el desarrollo de las relaciones comerciales externas de la nación. En cambio, la política interna, -de connotación social y de fomento a la producción- no tenían un sentido estratégico para ese Estado. "Eran desechos de la política 'real'. En consecuencia, era un paquete que, para reducir costos fiscales, se podía descargar en los hombros de instituciones menores, tales como los Municipios y la Iglesia Católica."97

Durante ese período la proporción de escuelas municipales se concentró en las ciudades cabeceras de departamento: 23 en Santiago, 12 en Valparaíso, 8 en Caldera y 7 en La Serena. En las provincias figuraban 1 ó 2 por departamento o no existían, dependiendo de los recursos municipales disponibles y de la demanda escolar. ${ }^{98}$ La intervención estatal se extendió no sólo con la creación de escuelas en los lugares donde no había escuelas municipales sino con la utilización de diversos canales informativos: los reglamentos hacían operativa la ley. ${ }^{99}$ Además, involucró poco a poco mayor financiamiento y 
cobertura para la enseñanza primaria y para los municipios, -sin presupuesto adecuado- desligarse de responsabilidades. ${ }^{100}$ Con todo, no es fácil determinar si las municipalidades suscribieron una liberación o fueron compelidas, ya que éstas sobrellevaban disposiciones de un estrecho presupuesto, o si fue promovida a través de las leyes orgánicas que no hacían más que debilitar el funcionamiento municipal.

A estos factores se añadieron otros ligados al proceso electoral fijado en 1854. Estos comicios inauguraron la libertad electoral casi dos décadas antes de las elecciones parlamentarias. En contrasentido, los alcaldes elegidos democráticamente enfrentaron el exceso de encargos "sin libertad para concebir ni dineros para ejecutar," 101 lo que suscitó la oposición al centralismo y la reanimación -por un lapso- del movimiento comunalista. Los parlamentarios aprovecharon esta oposición para presionar la liberalización electoral desde los municipios hasta el poder ejecutivo no sin pretensiones: usar a los municipios como soportes en sus propias campañas políticas. En 1877 una ley puso fin a los representantes del Presidente en las municipalidades.

La ley de 1879 incluyó el Consejo de Instrucción Pública que unía y uniformaba la educación nacional a través de los planes de estudio y la supervisión de los establecimientos estatales y privados. La misma "organiza prolijamente, pero no transforma en modo alguno el espíritu didáctico contemporáneo (...) la sociedad tampoco había sufrido variación mayor, las capas sociales continuaban invariables. Estuvo en vigencia hasta 1927 y bajo su amparo se robustecieron las escuelas profesionales superiores," 102 porque establecía la gratuidad en la enseñanza secundaria y superior en instituciones con dependencia estatal y reglamentaba la existencia de al menos un centro secundario fiscal en cada provincia. Asimismo, se le atribuyó el abandono de la enseñanza secundaria femenina y el descuido de las enseñanzas de carácter técnico; ambas tuvieron que surgir bajo el patrocinio de otras entidades.

Durante el último cuarto del siglo XIX la oligarquía no pierde hegemonía como bloque decisorio en la política, la economía, el control de la sociedad y en los emergentes medios de comunicación. "Una minoría aristocrática conservadora, católica y ligada al dominio de la tierra primero, y más tarde, una

\footnotetext{
100 Algunos de los procedimientos municipales incluían solicitudes al Ministerio de traspaso de sus escuelas al sistema fiscal para garantizar los sueldos de los profesores (asumiendo sólo la mantención escolar), de aportes económicos a fin de completar los fondos que tendían a disminuir anualmente, todas las peticiones evitaban el cierre de las escuelas.

101 SALAZAR y PINTO. (1999): óp., cit, p. 277.

102 LABARCA. (1939): óp., cit, p. 175.
}

Rev. hist. edu. latinoam. Vol. 15. Año 2010, pp. 93 - 124 
combinación de aristócratas tradicionales y nuevos empresarios enriquecidos, controlan los destinos del país. Los grupos medios se multiplican pero aún no salen de su condición subalterna, mientras que los trabajadores urbanos y rurales, aún no cuentan como actores sociales."103

La ley de 1883 convenía en la construcción de escuelas primarias, contrato de profesores para escuelas normales, programas de estudios en el extranjero para profesores, servicio de mobiliario y materiales educativos. ${ }^{104} \mathrm{Si}$ los municipios ofrecían terrenos adecuados, tenían preferencia para construir escuelas. En ciertos aspectos, la legislación evidenció mayor nivel de exigencias hacia las municipalidades que autonomía o corresponsabilidad en el tema educativo local.

Cabe mencionar que entre 1881 y 1891, bajo los períodos presidenciales de D. Santa María y J. M. Balmaceda respectivamente, se intentaron llevar a la práctica los principios de la ley de 1860, período de intensa actividad pedagógica extendido hasta 1897 . Ahora bien, entre 1879 y 1884 Chile intervino en la Guerra del Pacífico que, indudablemente, puso trabas a la agenda gubernamental. Sin embargo el presupuesto nacional para la instrucción pública tendió a mantenerse, en 1879 registró \$ 1.083.944 y en 1892 ascendía a \$ 5.641.120, aunque seguía siendo mínimo para las necesidades de la población. ${ }^{105}$ El contexto socio-político envolvió rivalidades y conspiraciones, rebeliones internas, guerras civiles, expansión y reducción territorial, crisis económicas, fusión y división de partidos, nacientes alianzas y partidos políticos. Conjuntamente, los efectos de conflictos internacionales y desastres naturales. En la última década se instauró un régimen de gobierno parlamentario que traspasaba poder al Parlamento -compuesto por la clase dominante- y restringía facultades al Ejecutivo.

En el ámbito municipal, las leyes orgánicas siguieron vinculándose con la educación primaria. La ley de la Comuna Autónoma de 1891 en sus atribuciones se refería al sostenimiento de escuelas primarias y otros establecimientos educacionales costeados con fondos municipales, dotación de útiles, fijación de reglamentos y planes de estudio, promoción de asociaciones particulares e inspección de establecimientos de educación. ${ }^{106} \mathrm{El}$ presupuesto contemplaría

\footnotetext{
${ }^{103}$ PIIE, PROGRAMA INTERDISCIPLINARIO DE INVESTIGACIONES EN EDUCACIÓN (1984). Las transformaciones educacionales bajo el régimen militar. Vol. 1. Santiago, Compiladores, p. 10. 
los servicios designados al municipio, entre ellos la instrucción primaria gratuita. ${ }^{107}$ Asimismo, reproducía funciones municipales definidas en 1854 ampliando contenidos de seguridad, orden público y moralidad. El mejoramiento radicaba en la definición de fuentes de recursos para inversiones y gastos, aseguraba autonomía eliminando la función municipal de intendentes, gobernadores y subdelegados y estableciendo las Asambleas de Electores. Sin duda, representó el acceso al poder de la base ciudadana, pero prosperó sólo en el discurso y en el texto. Las rentas municipales convenidas se paralizaron y más tarde, se derogaron las asambleas. ${ }^{108}$

En el campo educativo el reglamento de 1898 consolidaba el papel la Inspección General en cada territorio bajo la dependencia del ministerio y de los visitadores como jefes inmediatos de directores, preceptores y ayudantes de las escuelas superiores y elementales. También creaba las comisiones departamentales presididas por el Gobernador para velar por el servicio de instrucción primaria local, -organismo desconcentrado del ministerio- y la inspección formaba parte en sus deliberaciones. En los hechos, la Inspección Departamental presentaba al Ministerio los presupuestos de gastos de instrucción primaria.

En educación, la segmentación social -malas condiciones para un sector- y la pluralidad de administraciones serán atributos permanentes. Rector y Consejo Superior se encarga de la universidad y de los liceos de hombres. El Ministerio del ramo gestiona las escuelas primarias y normales, los liceos de niñas y algunas escuelas comerciales y técnicas. El Ministerio de Industrias y Obras Públicas administra la incipiente educación técnica profesional. "La dualidad de subsistemas se refuerza también con la (...) formación de profesores: los maestros primarios en escuelas normales con 4 o 5 años de estudios postprimarios, y los profesores secundarios con 3 o 4 años de Universidad." 109

Al finalizar el siglo XIX el gobierno central abordaba todos los procesos escolares: fundación de escuelas, asignación de recursos, expedición de textos y materiales educativos, recopilación estadística, nombramientos y destituciones de los funcionarios. El Estado, -sin monopolizar- contemplaba que colegios privados y municipales tuvieran participación en la gestión educativa reconociendo su tradición y experiencia. No obstante, "a medida que se afianzaba el funcionamiento del sistema, quedaba en claro que los municipios no ejercerían

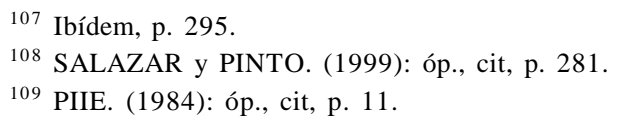


nuevamente funciones administrativas relevantes en relación a las escuelas primarias," 110 porque subsistían obstaculizados y carentes de presupuesto ${ }^{111}$ perjudicando sueldos de los profesores, infraestructura y equipamiento. En esencia, sin ingresos para solventar las obligaciones, las municipalidades incumplían con sus responsabilidades educacionales.

Sin duda, los aportes municipales a la educación nunca alcanzaron mayor notoriedad, respondieron más bien a la etapa que eran únicos sostenedores de las escuelas gratuitas. Ya en 1853 al Estado correspondía $\$ 42.185$ y al municipio $\$ 30.715$. El financiamiento proyectado para 1860 señalaba un aporte estatal de $\$ 237.731$ y uno municipal de \$70.000. En 1865 un $19 \%$ del presupuesto total destinado a la instrucción primaria eran aportes municipales. ${ }^{112}$ Es más, la década del ochenta empañó el financiamiento municipal por la pérdida de los ingresos locales, frenando los compromisos financieros que tradicionalmente habían aportado y disminuyendo presencia educativa en los centros de su dependencia.

El sistema educacional chileno, diseñado fundamentalmente a partir de la cuarta década siglo XIX no va a experimentar cambios significativos hasta 1920. Los principios de Estado Docente incluían una enseñanza primaria gratuita -sin llegar a toda la población- y una educación secundaria y superior selectiva. En los años venideros, los profesores y sus propias asociaciones serán gradualmente agentes con mayor protagonismo, los cuales desplegarán nuevos planteamientos frente a los problemas educacionales tanto históricos como recientes.

\section{CONCLUSIONES}

Los antecedentes históricos de la educación chilena -divididos en cinco ciclos- no tienen sino la pretensión de establecer una articulación de éstos con la trayectoria institucional del país, y básicamente con el rol "educativo" que cumplieron los cabildos en el Siglo XIX, luego denominados municipalidades, como entidades cuasi-naturales, anteriores al Estado y a las ordenaciones legislativas. Aunque el objetivo temático del artículo se concentra en el siglo en comento, el estudio se inició muy sucintamente, con la presencia de diversos grupos humanos extendidos a lo largo del territorio, -con su particular estructura social más comunitaria y horizontal- políticamente descentralizados y con ciertas

\footnotetext{
${ }^{110}$ EGAÑA. (2000): óp., cit, p. 74.

${ }^{111}$ Egaña plantea que el origen de la financiación que sustentaba la educación pública gratuita fue diverso distinguía entre ellos los del gobierno central, municipio, conventos, vecinos de las localidades y particulares. Los recursos de la educación privada provenía de sociedades filantrópicas y de los padres.

${ }^{112}$ Ibídem, p. 84.
} 
modalidades de instrucción intencionada que, evidentemente, configuraron nuestro primer componente de idiosincrasia e identidad social-histórica. De esta manera, no escapa ni aparta la existencia de un pasado precolombino y prehispánico, reconoce a Chile no sólo desde la versión colonial, enlazando historia, instituciones y cultura de sus pueblos originarios.

La etapa colonial mostró los primeros esfuerzos concernientes a la instrucción, el papel funcional y evangelizador de la enseñanza asumido por las órdenes religiosas, el trasplante de la institución peninsular denominada cabildo y sus múltiples funciones, las mutaciones sociales aplicadas arbitrariamente y la falta de un proceso educativo propiamente tal. En el orden ideológico, Chile muestra a través de su historia su condición de país conquistado en casi todos los ámbitos. En educación por ejemplo, los fundamentos que imperaron sobre la orientación de políticas de enseñanza, así como la pedagogía, las metodologías y los medios didácticos derivados de la misma, obtuvieron del Cristianismo y en forma sucesiva de la Ilustración sus bases de desarrollo.

Tras la emancipación, -asentada en la institucionalidad hispana y no en consensos y políticas propias- la confrontación fue la alternativa para conseguir una nueva regulación. Estas circunstancias, unidas a la hegemonía del poder militar y al surgimiento del poder político a partir de éste; fueron variables que condicionaron un largo período de gran inestabilidad social, geográfica y política. Es un hecho que la guerra persistió como factor histórico capital a lo largo del siglo. La existencia de factores prioritarios retrasó el desarrollo del sistema educativo, su implementación fue poco sistemática y en aspectos claves intermitente. De todas formas, la incorporación de la educación al mundo político, tuvo como consecuencia la contribución al proceso de consolidación del Estado.

La Independencia marcó un permanente y legítimo interés de instruir a todos los sectores sociales, pero la consecución fue mínima, -cargando inestabilidad, precariedad de recursos y preferencia en gastos militaresvoluntades y esfuerzos priorizaron la construcción del Estado, atendiendo por momentos los asuntos educativos. La necesidad expresada hacia la educación pública fue en principio funcional, de alcance en el fortalecimiento y consolidación del proyecto político de naturaleza republicana, básicamente se trataba de ampliar protagonismo con un Estado garante de ese servicio. Las nuevas administraciones manifestaron su preocupación a través del discurso político, reglamentaciones y planes de transformación y modernización. En su primera intervención decretó la conminación a los cabildos y los conventos a disponer escuelas primarias gratuitas, fondos para su mantenimiento y ayuda a los niños que no tenían recursos. 
A los particulares conflictos vividos se sumaron la disgregación social y económica y en el trayecto de configuración estatal prevalecieron antiguos y naturales intereses locales. Eran entornos concretos, opositores a un enfoque nacional arbitrariamente heredado de la Colonia que en ocasiones contenían exclusión y autoritarismo. La política oficial en ciernes ratificó la diferenciación y orden interno, pero no detuvo las aspiraciones de resistencia y alternatividad, guerras internas y externas se mantuvieron en el siglo XIX. En ese formato surgieron intereses suficientemente definidos que operaban bajo dispositivos de dominación, especialmente sobre clases sociales desfavorecidas. La cimentación -exclusivamente económica- consolidó la segmentación social en el sistema educativo nacional, entre otros. El Estado entonces, no transcurrió del modo democrático, fue rodeado de una restringida representatividad política y una reducida base social de apoyo.

Los proyectos preliminares giraron inversamente a partir de la tercera década del siglo XIX, probablemente porque hasta ese momento la sociedad civil carecía de una sólida organización y sus instituciones intermedias aún eran precarias. La educación pública fue detrás de las propuestas, -yacía en estado de postergación- estaba en manos del poder y del juego político y económico, partidarios o no a las iniciativas. La preocupación del Estado se vinculaba con la idea de civilizar y moralizar al pueblo en un proceso de modernización, pero no existía ni remotamente la obligación de garantizar la integración de todos los sectores sociales de una forma más abierta, equitativa y coherente.

La política educacional por ende surgía de la clase dominante compuesta por políticos, intelectuales, eclesiásticos, latifundistas y a todas las capas del mundo mercantil. En líneas de verticalidad las decisiones eran convenientes para el resto de la sociedad. La estructura educativa comprendía el nivel primario terminal -mínimo en debate y regulaciones- dirigido a la población mayoritaria y el nivel secundario y superior -más atendido- orientado a elites y a emergentes sectores medios. El desarrollo económico-productivo permaneció desligado de la enseñanza dudándose de sus virtudes, se decía que conocimientos escolares y requerimientos laborales eran innecesarios e incompatibles. En paralelo, las capas populares subsistían postergadas -se cerraba el círculo- y las coordenadas educación y movilidad social eran imperceptibles.

Puesto que el proyecto estatal no consideraba trascendente la educación para todos, no tuvo más remedio que buscar formas de consolidación política a través de instituciones que apoyaban esta tarea. En correspondencia, emprendió las bases del aparato público educacional en la cuarta década del siglo XIX con la fundación de la Universidad de Chile y la Escuela Normal de Preceptores, 
pero sin oportunidades efectivas para toda la población. A partir de 1850 se concentró en organizar la institucionalidad escolar fundando escuelas y dotando exigua y pausadamente de equipamiento e infraestructura, a la par intervino sobre la práctica escolar. Si bien la enseñanza contaba con instituciones, éstas no formaban parte de un sistema global que las potenciase. El modelo de educación estatal fue sobrepasando en cierta medida los modelos escolares existente, -municipios y conventos- exigiendo la alineación a sus políticas educativas. En esta dinámica, surgió el ministerio del sector con amplias atribuciones en materia de educación nacional, muchas de ellas, facultades que habían sido asignadas en principio a los municipios.

Al proceso de estatización educativa se unió el proceso de centralización, configurado dentro de un fenómeno más amplio de consolidación del EstadoNación. Por consiguiente, se redefinieron los centros de poder nacional de cara a los poderes subnacionales y asimilaron las atribuciones de la iglesia católica. Al mismo tiempo fue introduciéndose una percepción más o menos moderadora del Estado como única entidad que garantizaba la estabilidad, el progreso y el orden institucional.

Con posteridad a 1860 el Estado asumió nominalmente la función de organizar y sostener el sistema escolar, sin constituir novedad respecto de lo que se venía haciendo inauguró un marco de institucionalidad y de subordinación a las normas burocráticas dominantes mediante una política centralizada, diferenciada y autoritaria. Las medidas sólo aseguraron uniformidad en la política educativa y cierta estabilidad a través del apoyo financiero. La incipiente organización, la precariedad en las prácticas y la cobertura escolar no fueron satisfechas. El compromiso hacia la enseñanza primaria comprendía -en teoríagratuidad e integración de los sectores populares, segmentando las clases sociales y controlando la actividad pedagógica: una primaria pública dependiente del Estado y las municipalidades y una primaria particular dependiente de órdenes religiosas, sociedades filantrópicas o patrocinio privado.

Los compromisos educativos fijados por ley no fueron desarrollados íntegramente. Hubo más producción de documentos en términos de decretos, reglamentos y normativas que acciones decisivas para elevar el nivel educativo en el país. Frente a las disposiciones la educación nacional fue declarándose unitaria, estatal y centralizada. Los servicios educativos de responsabilidad local declinaron por la falta de financiamiento -la concesión de recursos nunca se dictó- y las rentas municipales acusaron cada vez mayor insolvencia. La política pública continuó la fundación de escuelas fiscales en diferentes comunidades y las escuelas municipales tendieron a desaparecer, porque el Estado las fundaba, 
reemplazaba o absorbía. Cada cierto período la cuestión educativa resurgía asociada a un marco de economía favorable o a una corriente de nuevos políticos presionando a los gobiernos de turno por las necesidades de la educación en su conjunto. Las soluciones a menudo parciales e incompletas reconocían responsabilidad estatal pero ignoraban los alcances en la cobertura y las condiciones laborales de los docentes.

En resumen, el siglo XIX estuvo caracterizado por los conflictos de autonomía al interior de las comunidades, las definiciones nacionales, la institucionalidad del país y el descuido de la educación pública. A pesar de todo, la educación pública trascendió en las manifestaciones de unidad. La legislación educativa no estuvo ausente y los textos constitucionales introdujeron los albores del principio de «Estado Docente". El Estado se atribuyó sin ninguna duda la función educadora. Las municipalidades en este contexto continuaron con sus obligaciones irrumpiendo otras circunstancias que, constituyeron verdaderas amenazas para su desempeño: enfrentaron la escasez de recursos económicos y la disminución de atribuciones en todos los ámbitos. El aparato local fue lentamente desmantelado para dar cimiento y arranque del aparato estatal. En el proceso de consecución del sistema educativo nacional fueron perdiendo posicionamiento los agentes municipales y ampliando presencia los agentes centrales, además quedaron excluidas las posibilidades de participación y responsabilidad compartidas de ambas entidades. Las leyes y reglamentos posteriores formalizaron el carácter centralizado de la educación nacional y un número menor de legislaciones municipales derivaron en la declinación de sus facultades y compromisos educativos.

\section{FUENTES}

CONSTITUCIÓN POLÍTICADELESTADODE CHILE. (1822).

CONSTITUCIÓN POLÍTICADELESTADODE CHILE. (1823).

MINISTERIODEL INTERIOR. (1828): Constitución Política de la República de Chile 1828.

MINISTERIO DEL INTERIOR. (1833): Constitución Política de la República de Chile 1833.

MINISTERIODE INSTRUCCIÓN PÚBLICA. (1863): Normas Reglamentarias para aplicar la Ley de Instrucción Primaria de 1860 del 1 de diciembre de 1863. Boletín de las Leyes y Decretos del Gobierno. Santiago, Ministerio de Instrucción Pública.

MINISTERIO DEL INTERIOR. (1891): "ley de Organización y Atribuciones de las Municipalidades No 4.111 del 24 de diciembre de 1891,"en: Boletín de las Leyes y Decretos. 
Moyra Castro Paredes

MINISTERIO DEL INTERIOR. (2006): 2000-2006 Memoria de la descentralización. Santiago, SUBDERE.

PROYECTODECONSTITUCIÓN PROVISORIAPARAELESTADODECHILE 1818.

\section{REFERENCIAS}

ALEMPARTE, Julio. (1940): El cabildo en Chile Colonial. Orígenes municipales de las repúblicas hispanoamericanas, pp. 19-92. Santiago, Ediciones de la Universidad de Chile.

BENGOA, José. (2000): Historia del pueblo mapuche. Siglo XIX y XX, pp. 11-71. Santiago, LOMEdiciones.

CAMPOS, Fernando. (1960): Desarrollo educacional 1810 -1960, pp. 10-97. Santiago, Editorial Andrés Bello.

DE HINOJOSA Y NAVEROS, Eduardo. (1903): Estudios sobre la Historia del Derecho Español, pp. 18-29. Madrid, Imprenta del Asilo de Huérfanos del Sagrado Corazón de Jesús.

DE RAMÓN, Armando. (2001): Breve historia de Chile. Desde la invasión incaica hasta nuestros días (1500-2000). Buenos Aires, Editorial Biblos.

DE ROSALES, Diego. (1877): Historia General de el Reyno de Chile. Flandes Indiano. Tomo I, Libro I, pp. 1-179. Valparaíso, Chile, Imprenta del Mercurio.

DONOSO, Andrés. (2008): Educación y nación. Al sur de la frontera. Organizaciones mapuche en el umbral de nuestra contemporaneidad, 1880 - 1930. Santiago, Pehuén Editores.

EGAÑA, Loreto. (2000): La educación primaria popular en el siglo XIX en Chile: Una práctica de política estatal. Santiago, DIBAM, PIIE, LOM, Centro de Investigaciones Diego Barros Arana.

HALPERIN, Tulio. (1972): Historia Contemporánea de América Latina. Madrid, Alianza Editorial S. A.

HARING, Clarence. (1972): El Imperio Hispánico en América, Traducción de Horacio Pérez Silva. Buenos Aires, Solar/Hachette.

JOBET, Julio. (1970): Doctrina y praxis de los educadores representativos chilenos. Santiago, Editorial Andrés Bello.

LABARCA, Amanda. (1939): Historia de la enseñanza en Chile. Santiago, Editorial Universitaria. Publicaciones de la Universidad de Chile.

\begin{tabular}{l|l} 
Rev. hist. edu. latinoam. Vol. 15. Año 2010, pp. $93-124$ \\
\hline &
\end{tabular}


MOLINA, Miguel. (1996): El Municipio en América. Aproximación a su desarrollo histórico. Granada, Ediciones Adhara, S. L.

MONTECINOS, Egon. (2005): Antecedentes sobre la relación histórica centralismo y descentralización en Chile," en: Revista Venezolana de Gerencia, 31, Venezuela.

NICKSON, Andrew. (2005): La descentralización política, en: I. CRESPOy A. MARTÍNEZ (Eds.), Política y gobierno en América Latina. Valencia, Tirant lo Blanch.

PIIE, PROGRAMA INTERDISCIPLINARIODE INVESTIGACIONES ENEDUCACIÓN (1984): Las transformaciones educacionales bajo el régimen militar. Vol. 1 y 2. Santiago.

SALAZAR, Gabriel y PINTO, Julio. (1999): Historia contemporánea de Chile I. Estado, legitimidad, ciudadanía. Santiago, Lom Ediciones.

SÁNCHEZ, Luis. (1972): Historia general de América. 3 Vols. (10ª ed.). Madrid, Ediciones Rodas S. A.

SILVA, Fernando. (1962): Tierras y pueblos de indios en el Reino de Chile. Esquema histórico-jurídico. Santiago, Universidad Católica de Chile.

VALENZUELA, Esteban. (1999): Alegato histórico regionalista. Santiago, Ediciones Sur.

VERGARA, Jorge. (2001): El Estado y las organizaciones sociales en Chile. (Versión preliminar). Ponencia presentada en el Tercer Encuentro Latinoamericano ISTR-LAC. Buenos Aires, Argentina.

WEINBERG, Gregorio. (1995): Modelos educativos en la historia de América Latina. Buenos Aires, A•Zeditora S.A., UNESCO, CEPAL, PNUD.

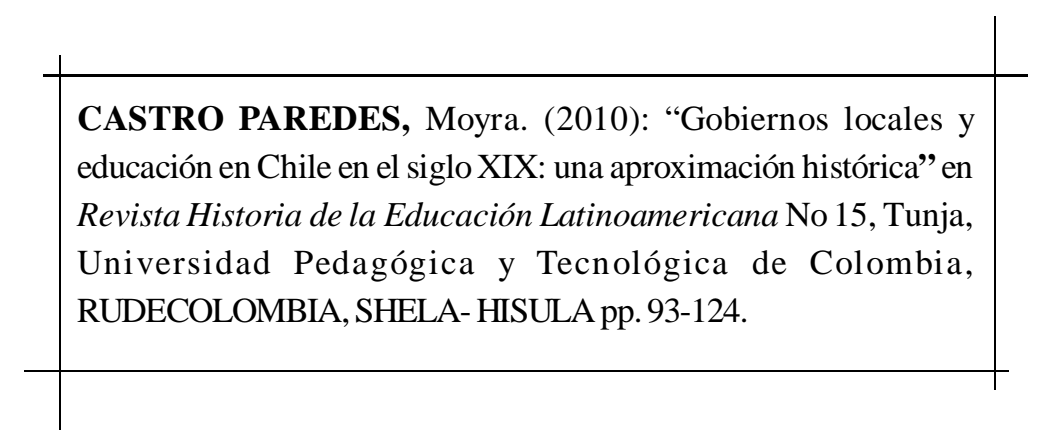

Rev. hist. edu. latinoam. Vol. 15. Año 2010, pp. 93 - 124 